Special Issue of the 8th International Advances in Applied Physics and Materials Science Congress (APMAS 2018)

\title{
Computational Fluid Dynamics Analysis of Titanium Outflow Pipe Implant for Glaucoma Treatment in Biomechanical Engineering
}

\author{
Ö. KARAÇALI* \\ Istanbul University Cerrahpaşa, Faculty of Engineering, Department of Mechanical Engineering, \\ Avcllar, Istanbul, Turkey
}

\begin{abstract}
Outflow pipe implant with check valve is a new glaucoma ocular tension treatment, developed primarily to correct the deteriorated intraocular fluid circulation in glaucoma disease. The research focus is to analyze a new outflow pipe implant with check valve material behavior for improving intraocular fluid outflow structure. Very few computational studies have considered both the mechanical and fluid flow impact of outflow pipe implant with check valve. There is non-available literature on outflow pipe implant with check valve structure and appropriate material selection to release the aqueous humor in intraocular stabilized pressure. The CFD-ANSYS simulation model was investigated for realization of realistic fluid flow velocity and pressure of aqueous humor behavior in microenvironment of the suprachoroidal space. The static structure and the von Mises stress for failure mode were studied to explore geometrical shape and material deformation structure by finite element method in ANSYS. Research results show affirmatively that structural analysis data correlates with fluid dynamics data in agreement.
\end{abstract}

DOI: 10.12693/APhysPolA.135.561

PACS/topics: computational fluid dynamics (CFD), outflow pipe, ANSYS, check valve, glaucoma, titanium

\section{Introduction}

Glaucoma is a major eye disorder causing irreversible blindness treated by important device inventions in industrialized countries [1-3]. In this research, basic concepts of adaptive implant for minimally invasive glaucoma treatment [4] were studied as shown in Fig. 1. At present, commercial implants still needs to be developed further due to uncontrolled AH flow pressurevelocity and hypotony [5] occurring inside of the implant devices [6]. In this investigation, CFD analysis-Fluent

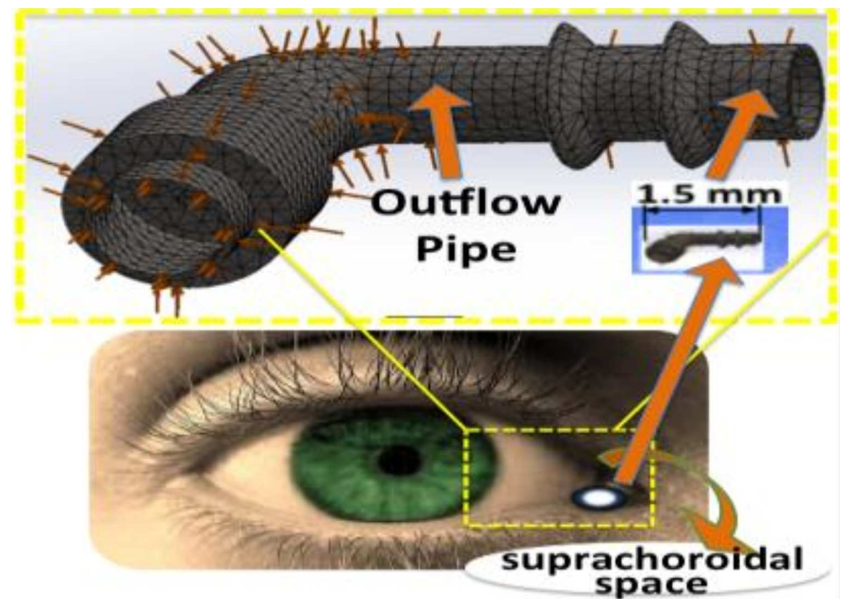

Fig. 1. Meshed model of OPIV.

*e-mail: ozdogank@istanbul.edu.tr

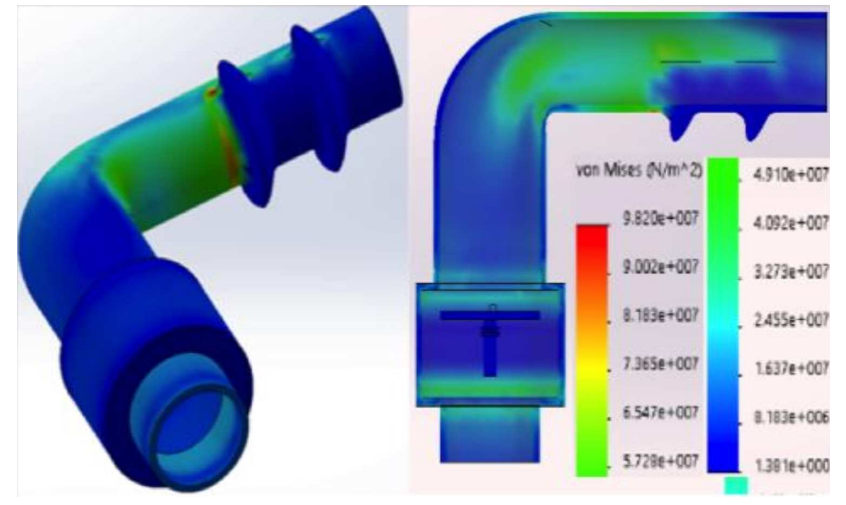

Fig. 2. The von Mises stress of OPIV.

ANSYS [7], was used to observe the pressure and velocity level 8-22 $\mathrm{mmHg}$, and to obtain the long term structural static von Mises stress energy [5] under AH fluid flow as displayed in Fig. 2.

\section{Materials and method: experimental procedure}

The CFD technique was used to foster a novel outflow implant. The Navier-Stokes equation for the fluid mechanics was employed for Newtonian and incompressible fluid properties of AH. A model of outflow pipe implant with check valve (OPIV) was drawn in Solidworks and then transferred to CFD-ANSYS fluent analysis to resolve velocity of the flow as displayed in Fig. 3 and pressure of the flow effect as exhibited in Fig. 4 associated with OPIV. This activity responded the computational velocity and pressure research simultaneously to 

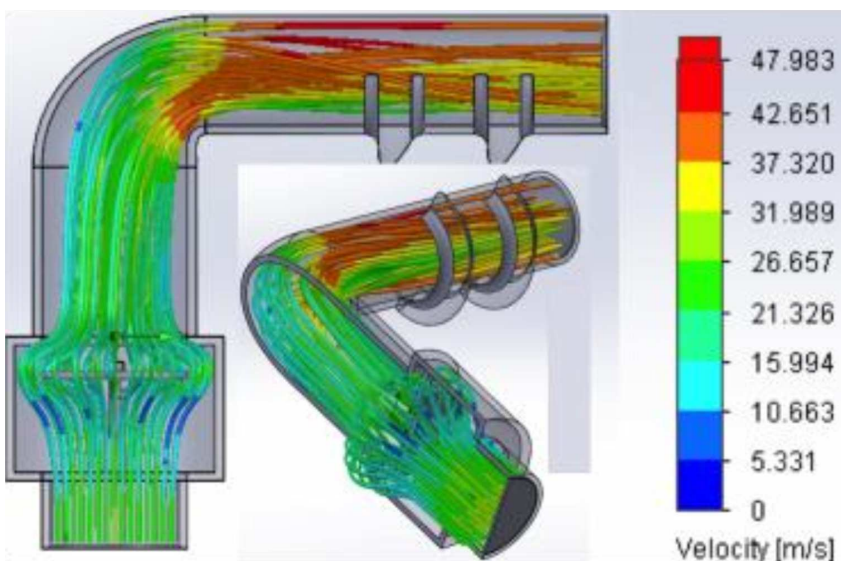

Fig. 3. Velocity of the flow in OPIV.

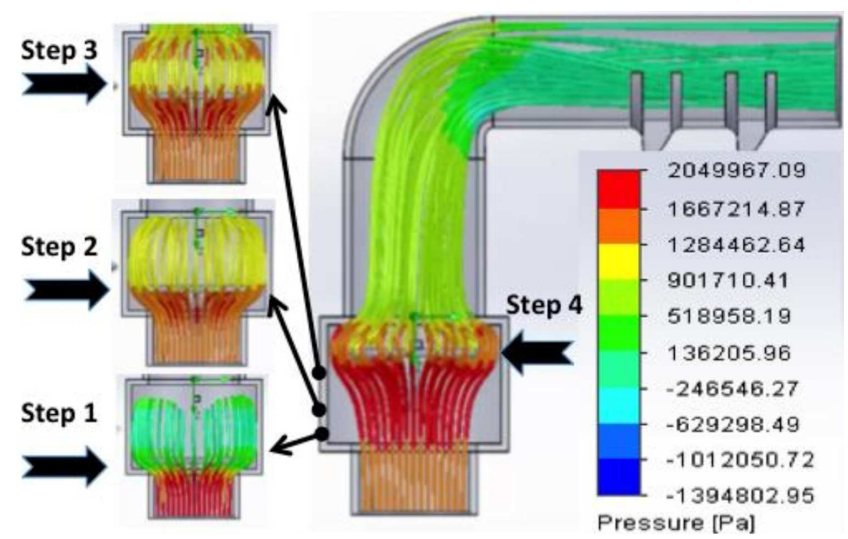

Fig. 4. Pressure of the flow in OPIV.

deliver robust results. The AH outflow for mass conservation was managed under incompressible fluid by modified Goldman flow equations [6]. AH discharge rate $Q_{i n}$, flow rate $Q$, pressure $Q_{0}$, facility indicator $C$, the intraocular pressure $P$, vessel pressure $P_{\mathrm{e}}$ are presented in (1) correspondingly:

$$
Q_{\text {in }}+Q=C\left(P-P_{e}\right)+Q_{0} .
$$

Equation (1) was used to measure outflow usage rate. The OPIV wall was supposed to be a non-slip surface and was $1.4 \mathrm{~mm}$ in diameter. Aqueous humor $(\mathrm{AH})$ was modeled as an incompressible liquid at a density of $1060 \mathrm{~kg} / \mathrm{m}^{3}$ and negligible viscosity flows steadily through a pipe of constant diameter. Approximately 186005 unstructured meshes were produced for OPIV. A check valve was developed to stop an inverse run in OPIV. The irregular AH flow conditions in specific, the fluid pressure within the check valve could develop more than $25 \mathrm{~mm} \mathrm{Hg}$ to grasp the valve hinge (lid) fully open, if less than $10 \mathrm{~mm} \mathrm{Hg}$ to hold the valve hinge completely shut. Consequently, the AH fluid flow was drastically disturbed by the dynamic behavior of the valve hinge as displayed in Fig. 4. The 3D analysis of the check valve was analyzed for the von Mises stress criteria as given in Fig. 5. As can be seen in Fig. 6, during flow of the AH, micro check valve strain occurred when pres-

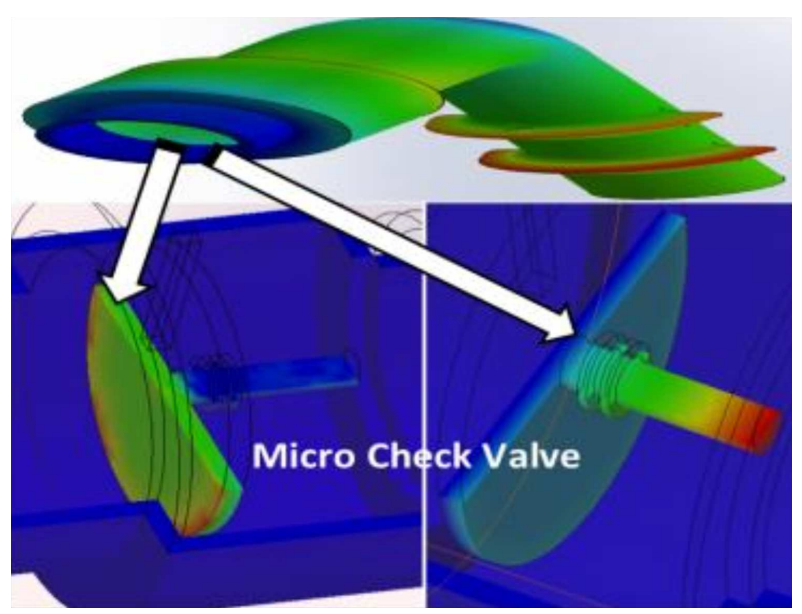

Fig. 5. The von-Mises criteria of OPIV.

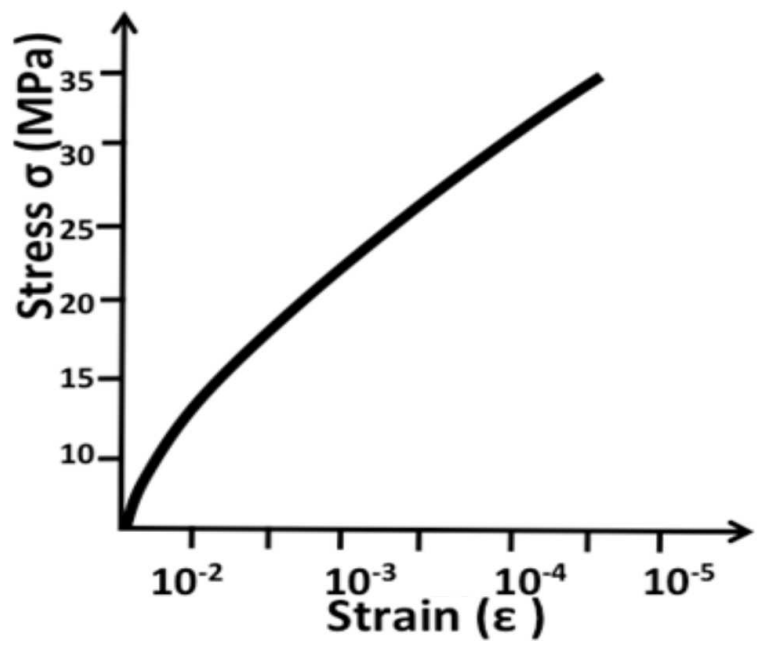

Fig. 6. Stress-strain rate in OPIV.

sure caused internal stresses. True static evaluation calculated stresses, strains (displacements), and strengths in the result of enforced loads when long term usage of OPIV system in Fig. 6.

When AH flow was applied to OPIV, the implant distorted, and the pressure outcome of flow was transferred in the pipe of the OPIV. The outward pressure, due to velocity induced inner forces and responses, provided the implant pipe into balance level, when check valve lid was fully open, as shown in Fig. 5. The pressure area in the check valve showed maximum pressure level of 2049967.09 Pa during flow of the AH in OPIV, as shown in Fig. 6.

\section{Results and discussion}

A new check valve was devised and realized inside of the OPIV, as shown in Fig. 5. This valve was required to turn on in 2000-4000 $\mathrm{Pa}$ pressure range to prevent hypotony. The reliefs of static pressure for $2.1 \mathrm{ml} / \mathrm{min}$ AH flow was modeled on the prototype, as exhibited in Fig. 4. This figure displays the pressure fall reaction of 
the check valve of OPIV throughout the flow period as the flow of $\mathrm{AH}$ was at $1.9 \mathrm{ml} / \mathrm{min}$. AH flow in the new modeled prototype dropped internal occular pressure to appropriate value of $798.76 \mathrm{~Pa}$ from $2431.50 \mathrm{~Pa}$. The critical drawback of implant resolved by check valve was able to control the flow of the AH inside the OPIV.

\section{Conclusion}

CFD simulation showed significant achievement how biofluidic AH flows may perform through OPIV before the real system established. The check valve was successfully applied with $2.10 \mathrm{ml} / \mathrm{min}$ flow rate, and then the pressure fell to $829.64 \mathrm{~Pa}$ in OPIV. CFD model of OPIV was achieved for correct flow of the AH, and was controlled by check valve. The physical experience of CFD helped the OPIV parameters to be estimated during flow of the AH. Therefore, ocular implant with the check valve design in this research revealed the potential improvement for pressure regulation.

\section{Acknowledgments}

This research is supported by project (no: 82751) of the Scientific Research Foundation (BAP), Istanbul University-Cerrahpaşa, Turkey.

\section{References}

[1] M. Hovakimyan, Trans. Vis. Sci. Technol. 4, 1 (2015).

[2] D.T. Manasses, L. Au, Ophthalmol. Ther. 5, 135 (2016).

[3] S. Siewert, Biomed. Micdev. 19, 78 (2017).

[4] J.M. Sherwood, PLoS ONE 11, 80 (2016).

[5] E. Kara, Comp. Met. Biomech. Biomed. Eng. 13, 655 (2016).

[6] J.G. Crowston, R.B. Weinreb, Curr. Opin. Ophthalmol. 16, 94 (2005).

[7] R.F. Brubaker, Exp. Eye Res. 78, 633 (2004). 